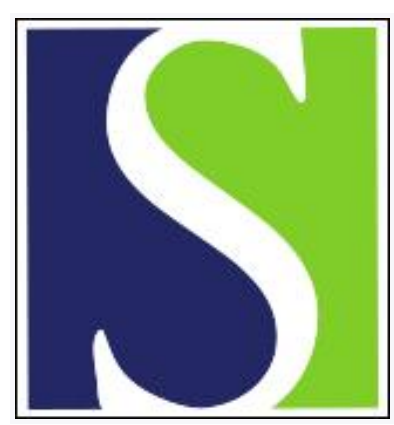

Scand J Work Environ Health 1988;14(5):317-321

https://doi.org/10.5271/sjweh.1913

Issue date: Oct 1988

Prevalence of risk factors for coronary artery disease among day and shift workers.

by Knutsson A, Åkerstedt T, Jonsson BG

Affiliation: National Institute for Psychosocial Factors and Health, Stockholm, Sweden.

The following article refers to this text: 2010;36(2):142-149

This article in PubMed: www.ncbi.nlm.nih.gov/pubmed/3201192 


\title{
Prevalence of risk factors for coronary artery disease among day and shift workers
}

\author{
by Anders Knutsson, MD, ${ }^{1}$ Torbjörn Åkerstedt, PhD, ${ }^{1}$ Björn G Jonsson, DrMedSc ${ }^{2}$
}

\begin{abstract}
KNUTSSON A, ÅKERSTEDT T, JONSSON BG. Prevalence of risk factors for coronary artery disease among day and shift workers. Scand J Work Environ Health 14 (1988) 317-321. Several recent studies have indicated that shift work is associated with increased risk of coronary artery disease. In this crosssectional study 361 shift workers were examined with respect to some major risk factors for coronary artery disease; 240 day workers constituted the reference group. A higher proportion of shift workers smoked (54 versus $39 \%$ ). Shift workers also had significantly higher levels of serum triglycerides (1.61 versus $1.43 \mathrm{mmol} / \mathrm{l}$ ). Body mass index and the blood pressure and total cholesterol levels did not differ between the groups. Multiple regression analyses demonstrated that shift work was significantly related to serum triglyceride levels also when age, smoking, body mass index, and other variables were controlled for. It was concluded that shift work is associated with several risk factors for coronary artery disease.
\end{abstract}

Key terms: blood pressure, cholesterol, coronary heart disease, cross-sectional study, ischemic heart disease, shift work, smoking, triglycerides.

Shift work has been associated with sleep disturbances and gastrointestinal disease $(2,4,11,20)$. Recent reports have also indicated increased risk of ischemic heart disease in shift workers $(1,3,14,15)$. Very few studies exist, however, of traditional risk factors among shift workers. Although Thelle et al (19) found elevated serum triglyceride levels among shift workers, it was not clear whether the elevated level was related to body constitution, smoking, age, or other factors. Rosen et al (18) conducted a survey of about 12000 subjects belonging to different occupational groups in Sweden. They found that day workers smoked less than those with "other work schedules," but their report lacked information about possible confounders.

The present study was aimed at comparing shift and day workers with respect to risk factors, eg, total cholesterol, triglycerides, smoking, and high blood pressure, for coronary artery disease. Particular care was taken to select companies where the work load and socioeconomic background would be similar between the shift and day workers.

\section{Subjects and methods}

The subjects consisted of 601 male blue-collar workers in three plants in the north of Sweden. Two plants manufactured paper and one produced carboxymethyl cellulose.

\footnotetext{
1 National Institute for Psychosocial Factors and Health, Stockholm, Sweden.

2 University College, Sundsvall-Härnösand, Sweden.
}

Reprint requests to: Dr A Knutsson, National Institute for Psychosocial Factors and Health, Box 60210, S-104 01 Stockholm, Sweden.
The shift workers $(\mathrm{N}=361)$ worked a rotating threeshift schedule and were process operators with a considerable amount of manual work. The shifts changed at 0600,1400 , and 2200 . Table 1 shows the shift schedule at the three plants. The day workers $(\mathrm{N}=240)$ were predominantly maintenance men who worked $40 \mathrm{~h}$ a week. The average income of the shift workers exceeded that of the day workers by approximately $17 \%$. The data were collected in 1975 and 1976.

All the subjects filled out a short questionnaire which included questions about the work schedule, the physical work load, psychosocial factors, smoking habits, and current medical symptoms. Smoking habits were recorded in terms of the daily consumption of tobacco. A worker with a daily consumption of one cigarette or more (for pipe smokers one gram of tobacco) was defined as a smoker.

The coded answers for the following six questions were added to form an index (physical index) measuring physical strain at work:

Is your work site comfortable?

Are machines and tools good enough?

Can you change positions during work?

Is your work too physically demanding?

Does your work require heavy lifting?

Is it possible to reduce the physical demands at your work site?

The score sum of the answers for the following nine questions were computed to measure the psychosocial work environment (psychosocial index):

Is your work too mentally demanding?

Is the planning of your work too irregular? 
Table 1. The shift schedule. ( $N=$ night shift, $M=$ morning shift, $A=$ afternoon shift, $-=$ day off)

\begin{tabular}{|c|c|c|c|c|c|}
\hline Workplace & Week 1 & Week 2 & Week 3 & Week 4 & Week 5 \\
\hline $\begin{array}{l}\text { Papermill } 1 \\
\text { Papermill } 2\end{array}$ & $\begin{array}{l}\text { NNNN }--- \\
\text { MMMMAAA }\end{array}$ & $\begin{array}{l}M M-A A A M \\
A-N N N N-\end{array}$ & $\begin{array}{l}--\mathrm{MMMM}- \\
------\end{array}$ & AAA - NNN & $-\ldots \ldots \ldots$ \\
\hline Chemical plant & $M M-A A A M$ & ------ & $A A A-N N N$ & - - MMMM - & NNNN $\ldots \ldots$ \\
\hline
\end{tabular}

Table 2. Subject characteristics of the day and shift workers. (NS = not significant)

\begin{tabular}{|c|c|c|c|c|c|c|c|}
\hline \multirow[t]{2}{*}{ Characteristic } & \multicolumn{3}{|c|}{$\begin{array}{l}\text { Day workers } \\
(\mathrm{N}=240)\end{array}$} & \multicolumn{3}{|c|}{$\begin{array}{l}\text { Shift workers } \\
\qquad(N=361)\end{array}$} & \multirow{2}{*}{$\begin{array}{c}\mathrm{P}- \\
\text { value }\end{array}$} \\
\hline & Mean & SD & $\%$ & Mean & SD & $\%$ & \\
\hline Age (years) & 44.8 & 11.7 & . & 43.2 & 11.8 & . & NS \\
\hline Duration of employment (years) & 18.5 & 10.9 & . & 15.2 & 9.6 & . & 0.001 \\
\hline Smokers & . & . & 39 & & & 54 & 0.001 \\
\hline Body mass index & 25.9 & 3.3 & . & 25.8 & 3.4 & - & NS \\
\hline Physical index & 1.5 & 1.3 & . & 1.7 & 1.4 & . & NS \\
\hline Psychosocial index & 1.3 & 1.5 & . & 1.6 & 1.4 & . & 0.005 \\
\hline Systolic blood pressure $(\mathrm{mm} \mathrm{Hg})^{a}$ & 139.7 & 18.3 & . & 139.7 & 16.3 & . & NS \\
\hline Diastolic blood pressure $(\mathrm{mm} \mathrm{Hg})^{a}$ & 83.3 & 11.2 & . & 83 & 10.6 & - & NS \\
\hline Hypertension (self-reported) & . & . & 18 & . & . & 14 & NS \\
\hline Total cholesterol (mmol/I) & 5.95 & 1.13 & . & 5.96 & 1.16 & - & NS \\
\hline Triglycerides (mmol/l) & 1.43 & 0.61 & . & 1.61 & 0.82 & . & 0.01 \\
\hline Blood glucose (mmol/l) & 4.9 & 0.9 & . & 4.9 & 1.0 & . & NS \\
\hline
\end{tabular}

a $1 \mathrm{~mm} \mathrm{Hg}=133.3 \mathrm{~Pa}$.

Do you have to do too much overtime work? Is the working speed too dependent on machines? Is the working speed too dependent on fellow workers? Do you have too many job tasks?

Are you satisfied with your job?

Are you satisfied with the management?

Does the job give enough opportunites to take a break?

The reliability tests yielded Cronbach's coefficient alphas of 0.53 and 0.58 for the physical and psychosocial indices, respectively.

Venous blood samples were drawn from an arm vein in the morning after a night's sleep. The subject fasted from 2400 the night before. Plasma was centrifuged within $2 \mathrm{~h}$, stored in a refrigerator at $4^{\circ} \mathrm{C}$, and analyzed within $3 \mathrm{~d}$. The blood plasma was analyzed by an autoanalyzer according to routine methods of a major hospital laboratory. In this paper the results of the total cholesterol, triglycerides, and blood glucose tests are reported.

Body weight (BW) in kilograms and height $(\mathrm{H})$ in meters were measured, and the body mass index (BMI) was calculated $\left(\mathrm{BMI}=\mathrm{BW} / \mathrm{H}^{2}\right)$. The diastolic and systolic blood pressures were measured with a sphygmomanometer with the subject supine after $5 \mathrm{~min}$ of rest.

\section{Statistical methods}

The significance of the differences between the mean group values was tested by Student's t-test and the chisquare test (two-tailed). Stepwise multiple regression analyses and reliability tests were performed by an SPSS program (16).

\section{Results}

Table 2 shows that the mean age of the shift workers did not differ significantly from that of the day workers. The duration of employment was significantly longer for the day workers. A higher proportion of shift workers smoked. The shift workers also had significantly higher levels of serum triglycerides. The body mass index, blood pressure, and the total cholesterol and blood glucose levels did not differ between the groups. The self-rated physical work conditions did not differ, but the shift workers reported a significantly lower quality of psychosocial work conditions.

Serum triglyceride concentrations are usually associated with age and body weight, and, in order to compute the relation between shift work and the serum triglyceride levels, we performed a multiple regression with the serum triglyceride concentrations as the dependent variable. Independent variables were age, body mass index, smoking, shift work, and the physical and psychosocial indices. Table 3 shows that the serum triglyceride levels were significantly predicted by body mass index, smoking, and shift work. We also tested the interaction between smoking and shift work, but no interaction was found.

In addition smoking, the other predictor of coronary artery disease that differed between the groups, was subjected to a regression analysis. The independent variables were shift work, age, and the physical 
and psychosocial indices. This analysis yielded a significant association only between smoking and shift work (standardized regression coefficient $=0.15$, $\mathrm{P}<0.001$ ).

Table 4 shows the proportion of subjects with increased levels of serum lipids. In all, $55 \%$ of the shift workers and $57 \%$ of the day workers were obese (defined as BMI $>25$ ). Twenty percent of both the day and the shift workers had a diastolic blood pressure exceeding $94 \mathrm{~mm} \mathrm{Hg}(12.5 \mathrm{kPa})$.

In table 5 the prevalence of the three major risk factors for coronary artery disease, ie, increased serum lipids, high blood pressure, and smoking, is presented. "Increased serum lipids" was defined as a total cholesterol level higher than $5.1 \mathrm{mmol} / \mathrm{l}$ or triglyceride levels higher than $2.2 \mathrm{mmol} / \mathrm{l}$. "High blood pressure" was defined as a diastolic blood pressure higher than $94 \mathrm{~mm} \mathrm{Hg}(12.5 \mathrm{kPa})$.

\section{Discussion}

The present cross-sectional study showed that smoking and high serum triglyceride levels were more prevalent among the shift workers than the day workers.

The three leading predictors of coronary artery disease are hypercholesterolemia, hypertension, and cigarette smoking. The role of elevated serum triglycerides as a separate risk factor for atherosclerosis and coronary artery disease is unclear, however. Thus Hulley et al (13) have argued that the Western Collaborative Study does not demonstrate that serum triglyceride levels are an independent risk factor. On the other hand Carlsson \& Böttiger (7) have concluded that serum triglycerides are a risk factor for "hard" end points of coronary artery disease. This argument is supported by the findings of the Stockholm Prospective Study $(6,7,8)$.

Hypertriglyceridemia has been noted to be a common finding in men with coronary artery disease (5). Moreover, it is frequently accompanied by obesity and abnormal glucose tolerance. The difficulty in interpreting triglyceride values, as well as their frequent association with hypercholesterolemia has prevented hypertriglyceridemia from emerging as a separate risk factor.

In the present study body mass index was the most powerful predictor of the serum triglyceride levels. Interestingly, however, this variable did not differ between the two groups studied and cannot be a contributor to the observed difference in triglyceride levels between the groups.

Smoking, however, is known to affect lipids, and the groups differed significantly with respect to this variable. Thus part of the observed difference between the groups may have been due to smoking.

Yet there still remains a significant, independent contribution from shift work. The reason for this finding is not clear, but one explanation may be dietary habits
Table 3. Last step in the step-wise regression analysis with serum triglyceride level as the dependent variable.

\begin{tabular}{lrccc}
\hline Predictor & $\begin{array}{c}\text { Regression } \\
\text { coefficient }\end{array}$ & t-Value & $\begin{array}{c}\text { Standardized } \\
\text { regression } \\
\text { coefficient }\end{array}$ & P-value \\
\hline Shift work & 1.86 & 2.19 & 0.12 & 0.03 \\
Body mass index & 70.52 & 7.57 & 0.32 & 0.000 \\
Smoking & 3.09 & 3.11 & 0.21 & 0.002 \\
Constant & -5.45 & 2.12 & & 0.035 \\
\hline
\end{tabular}

$R^{2}(\operatorname{Ad})=0.14, F(M o d)=15.47(P<0.001)$.

Table 4. Proportion of study subjects with increased levels of total cholesterol and triglycerides.

\begin{tabular}{lcccc}
\hline & $\begin{array}{c}\text { Day } \\
\text { workers } \\
(\%)\end{array}$ & $\begin{array}{c}\text { Shift } \\
\text { workers } \\
(\%)\end{array}$ & $\chi^{2}$ & P.value \\
\cline { 2 - 5 } $\begin{array}{l}\text { Cholesterol } \\
\text { (mmol/I) }\end{array}$ &. &. & 1.83 & NS \\
$\leq 5.1$ & 51 & 56 &. & $\cdot$ \\
$5.2-7.8$ & 45 & 39 &. & $\cdot$ \\
$\geq 7.9$ & 5 & 5 & $\cdot$ & $\cdot$ \\
$\begin{array}{l}\text { Triglycerides } \\
\text { (mmol/l) }\end{array}$ &. &. & 10.5 & 0.01 \\
$\leq 2.2$ & 86 & 76 & $\cdot$ & $\cdot$ \\
$2.3-5.6$ & 9 & 12 & $\cdot$ & $\cdot$ \\
$\geq 5.7$ & 5 & 12 & $\cdot$ & $\cdot$ \\
\hline
\end{tabular}

Table 5. Prevalence of major risk factors for coronary artery disease (serum lipids, high blood pressure and smoking) among the day and shift workers.

\begin{tabular}{lrrrrr}
\hline \multirow{2}{*}{$\begin{array}{l}\text { Number } \\
\text { of risk } \\
\text { factors }\end{array}$} & \multicolumn{2}{c}{ Day workers } & & \multicolumn{2}{c}{ Shift workers } \\
\cline { 2 - 3 } \cline { 5 - 6 } & $N$ & $(\%)$ & & $N$ & $(\%)$ \\
\hline 0 & 54 & 23 & 68 & 19 \\
1 & 103 & 43 & & 142 & 39 \\
2 & 74 & 31 & 124 & 34 \\
3 & 9 & 4 & 27 & 8 \\
\hline
\end{tabular}

$\chi^{2}=5.29, P<0.15$ (not significant).

or alcohol consumption, neither of which had been included in the present study.

We do not think that the strong relation between shift work and the increased levels of triglycerides was caused by a phase-shift of the circadian rhythm. First, the blood specimen was drawn from both the shift and day workers in the morning after a night's sleep. Second, the analyses did not yield any association between shift work and other blood variables that have the same diurnal rhythm as triglycerides.

Elevated levels of serum triglycerides in shift workers have been reported also by Thelle et al (19) and Orth-Gomer (17). In an experimental study the latter demonstrated that the type of shift schedule used might affect the serum triglyceride levels. Thus a group of policemen showed lower levels of serum triglycerides during counterclockwise shift rotation than in clockwise rotation. 
In the present study smoking was more common among the shift workers. There have been very few studies which have compared shift and day workers with respect to smoking behavior. In the Tromso heart study project (19) a higher prevalence of smoking was reported for shift workers than for day workers (64.9 versus $54.8 \%$ ). The level of significance was not reported. In a recent Swedish population survey day workers smoked less than those with "other work schedules" (18). However, no information on work schedules or possible confounders was provided. The investigations by Angersbach et al (4) indicated that smoking substantially contributes to gastrointestinal disease among shift workers. The percentage of smokers was very high $(75 \%)$, but no figures were given for day workers.

Why, then, do shift workers smoke more than day workers? One explanation may be that there is a selection of smokers into shift work. Such a selection could operate through, eg, socioeconomic or marital status. Previous investigations have shown that people from lower social strata, blue-collar workers, and people with low education smoke more than other socioeconomic groups $(9,10,12,18)$. However, in the present study, we had excluded white-collar workers and foremen. In addition, those shift and day workers which were included in the study had very similar living and economic conditions. Actually, the shift workers earned somewhat more than the day workers, a fact which should have suggested a lower prevalence of smoking. Unfortunately we did not collect any data on marital status in the present study, but in a current survey of blue-collar workers in one of the three plants, we did not find that marital status was a significant confounder with respect to smoking among the day and shift workers (unpublished data).

Another possible cause of smoking might be the work environment or the work task. However, the work environment was similar for the day and shift workers in 1975-1976. When the study was carried out, there were very few restrictions on smoking in the three plants studied. Both the day and shift workers could very easily take a break and smoke. In addition very similar ratings were obtained for the physical work conditions, and the total number of workhours was $10 \%$ lower for the shift workers. Furthermore, the mental load of the work task did not seem to explain the smoking behavior. Another, more likely explanation for the difference in smoking behavior is that smoking is influenced by the workhours, perhaps as a stimulant or as a way to pass time during the long night shift. The data do not, however, allow us to draw any definite conclusions.

The results of the present study, together with previous findings, support the hypothesis that shift work is related to risk for coronary heart disease. This greater risk seems, at least partially, to be due to wellknown risk factors, for example, smoking. However, in a recent study reporting association between shift work and coronary artery disease, a higher proportion of shift workers smoked, but the association between shift work and coronary artery disease remained significant also after age and smoking habits were controlled for (14). Thus it is too early to rule out the possibility of a direct association between shift work and coronary artery disease independent of mediation through established risk factors.

As cardiovascular disease is the most common cause of death in industrialized countries, any links with shift work would mean that the harmful effects of shift work on health would have to be regarded as more serious than has previously been thought the case.

\section{Acknowledgments}

This study was supported by grants from the Swedish Work Environment Fund (85-642).

\section{References}

1. Åkerstedt T, Knutsson A, Alfredsson L, Theorell T. Shift work and cardiovascular disease. Scand J Work Environ Health 10 (1984) 409-414.

2. Aanonsen A. Shift work and health. Universitetsforlaget, Oslo 1964.

3. Alfredsson L, Karasek R, Theorell T. Myocardial infarction risk and psychosocial work environment: An analysis of the male Swedish working force. Soc Sci Med 16 (1982) $463-467$.

4. Angersbach D, Knauth P, Loskant H, Karvonen MJ, Undeutsch K, Rutenfranz J. A retrospective cohort study comparing complaints and disease in day and shift workers. Int Arch Occup Environ Health 45 (1980) 127-140.

5. Carlsson LA. Serum lipids in men with myocardial infarction. Acta Med Scand 167 (1960) 399-413.

6. Carlsson LA, Böttiger LE. Ischemic heart disease in relation to fasting values of plasma triglycerides and cholesterol: Stockholm prospective study. Lancet 1 (1972) 865-868.

7. Carlsson LA, Böttiger LE. Serum triglycerides, to be or not to be a risk factor for ischaemic heart disease. Atherosclerosis 39 (1981) 287-291

8. Carlsson LA, Böttiger LE, Ảhlfeldt PE. Risk factors for myocardial infaretion in the Stockholm prospective study: A 14-year follow-up focussing on the role of plasma triglycerides and cholesterol. Acta Med Scand 206 (1979) 351-360.

9. Covey LS, Wynder EL. Smoking habits and occupational status. J Occup Med 23 (1981) 537-542.

10. Cummings RO, Shaper AG, Walker M, Wale CJ. Smoking and drinking by middle-aged British men: Effects of social class and town of residence. Br Med J 283 (1981) $1497-1502$.

11. Harrington JM. Shift work and health. Her Majesty's Stationery Office, London 1978.

12. Hay DR, Foster FH. The influence of race, religion, occupation and other social factors on cigarette smoking in New Zealand. Int J Epidemiol 10 (1981) 41-43.

13. Hulley SB, Rosenman RH, Bawol RD, Brand RJ Epidemiology as a guide to clinical decisions: The association between triglycerides and coronary heart disease. N Engl J Med 302 (1980) 1383-1389.

14. Knutsson A, Ảkerstedt T, Jonsson B, Orth-Gomer K. Increased risk of ischemic heart disease in shift workers. Lancet 2 (1986) 89-92. 
15. Koller M. Health risks related to shift work. Int Arch Occup Environ Health 53 (1983) 59-75.

16. Nie NH, Hull CH, Jenkins JG, Steinbrenner K, Bent DH. SPSS: Statistical package for the social sciences. Second edition. McGraw Hill, New York, NY 1975.

17. Orth-Gomer K. Intervention on coronary risk factors by adapting a shift work schedule to biological rhythmicity. Psychosom Med 45 (1983) 407-415.

18. Rosen M, Wall S, Hanning M, Lindberg G, Nyström L. Smoking habits and their confounding effects among occupational groups in Sweden. Scand J Soc Med 15 (1987) 233-240.

19. Thelle DS, Forde OH, Try K, Lehmann EH. The Tromso heart study. Acta Med Scand 200 (1976) 107118.

20. Thiis-Evensen E. Skiftarbeid og helse [Shift work and health]. Andreas Jakobsens Boktryckeri, Porsgrunn (Norway) 1949.

Received for publication: 21 January 1988 